\title{
Internal Environment and Organizational Performance of World Vision in Nairobi City County, Kenya
}

\author{
Sally Wairimu Ndungi ${ }^{1}$, Joyce Gacobo ${ }^{2}$ \\ ${ }^{1}$ Student, master's degree in business administration, Kenyatta University, Kenya \\ ${ }^{2}$ Department of business administration, Kenyatta University, Kenya
}

\section{ABSTRACT}

World vision in Nairobi operates in a very dynamic environment. These changes that keep happening in the environment whether anticipated or not determine the strategic objectives that World vision in Nairobi adopts in order to remain relevant in relation to its mission and vision. The general objective of this study was to investigate the influence of internal environment on organizational performance of World Vision in Nairobi City County, Kenya. The study specifically sought to examine the influence of organizational culture, employee competence, organizational structure and leadership style on the organizational performance. The study was guided by resource based view theory, Durkheim's theory of culture, contingency theory and expectancy theory. This study used descriptive survey research design. The unit of analysis was World Vision in Nairobi City County, Kenya. The accessible population was 95 respondents comprising of 10 managers and 85 support staff. The study conducted a stratified sampling method to sample the accessible population so as to ensure that all the cases are well represented. Simple random sampling method was used to select the respondents. Primary data was collected using questionnaires. The pilot study was conducted to 10 respondents who did not participate in the actual study to assess the face and content validity of the research instruments. The pilot study will also measure the characteristic of the reliability of the research instruments over the period of the research. Content analysis technique was used to analyse information obtained from the openended questions and reported in narrative form. Quantitative data was analyzed using descriptive statistics such as mean and standard deviation and presented in form of tables and figures. Inferential statistics such as correlation analysis and multiple regressions were used to determine the relationship between variables. The study found that organizational culture, employee competence, organizational structure and leadership styles had a positive and significant relationship with the organizational performance. This study concludes that a work environment that possesses organizational culture is driven by purpose and clear expectations. Competence among employees ensures that organization-funded training and professional development activities are cost-effective, goal-oriented and productive. The flow of information with an organizational structure can be used to promote faster decision-making. Leadership style develops structured and organised pathway for decision making which makes target more visible and clearer. The study recommends that the organization's leaders must communicate not only the values, but also the expected behaviors associated with each value to help the employees understand what is expected, which reduces uncertainty and ensures everyone is aligned on how things should be done at the organisation. In order to improve competencies, the organization should provide enough resources and motivate its employees. The organization should look at the current organizational structure and analyze whether its employees know their exact duties, who they supervise and whether they are being used to their maximum potential. The organizational 
International Journal of Business Management, Entrepreneurship and Innovation, Volume 3, Issue 3, 2021, PP 123-138, ISSN 2707-8027

BME

leaders should take time throughout the day to reflect to improve leadership style and skills and the managers should improve their leadership style by setting examples.

Key Words: Internal Environment, Organizational Performance, World Vision

DOI 10.35942/jbmed.v3i3.220

Cite this Article:

Ndungi, S., \& Gacobo, J. (2021). Internal Environment and Organizational Performance of World Vision in Nairobi City County, Kenya. International Journal of Business Management, Entrepreneurship and Innovation, 3(3), 123-138. https://doi.org/10.35942/jbmed.v3i3.220

\subsection{Introduction}

The environment in which business organizations operate is a complex, multi-focus dynamic and has a far reaching effect on such organization and the environment tends, shape the outlook, and goal of the organization by placing constraints on them (Derek, 2018). These constraints in the environment of organizations goal could be in the form of competition, this sets a limit on the goals specify by the organization. Atsegbua (2019) observe that since business makes demand on the society and the society makes demands on the business, managers in any organization must interact with and respond to environmental factors internal or external to their organizations. The organization, as a complex and dynamic socio-economic system, has an open character, being a component of the economy and society (Halmaghi, Iancu \& Băcilă, 2017). Duncan (2018) observe that integration of the organization into the environment in which it operates shows that the organization is in an adequate relationship with the environment, but also that this relationship allows the manifestation of the internal dynamism of the organization. In addition, Duncan (2018) observes that the activity of an organization is the result of the ongoing interaction between the organization and its environment.

The role of the internal environment in shaping the competitiveness of the firm is crucial (Hine \& Ryan, 2015). According to Tang (2018), the internal environment is typically described by its organizational structure, resources, climate and culture. Therefore, the organizations need to develop a climate that is conducive to creativity with a strong external focus on multiple stakeholders. Tang (2018) further observes that organizations survival and success depend on the appropriate adoptions to a complex and over changing environment. It is pertinent for top management of organization to identify opportunities and threats in the external environment. Organizational performance refers to the degree to which a firm's objectives are being or have been accomplished. Organizational performance also refers to a measure of how well a firm uses its resources to meet its goals and objectives (Olagunju \& Obademi, 2012). It is the process of measuring the actual results of a firm's policies and operations against its set goals and objectives. Parmenter (2015) observe that the performance of an organization is used to measure firm's overall financial and non-financial well-being over a given period of time.

Bennett, Lance and Woehr (2014) described organizational performance measurement as a process of assessing progress towards achieving pre-determined goals including information on the efficiency with which resources are transformed into goals and services, the quality of those outputs and outcomes, and the effectiveness of the organizational operations in terms of their specific contributions to organizational objectives. According to Luhangala and Anyieni (2019) 
International Journal of Business Management, Entrepreneurship and Innovation, Volume 3, Issue 3, 2021, PP 123-138, ISSN 2707-8027

\section{BNED}

the success of an organization is gauged from several indicators both qualitative and quantitative. These include: financial performance, meeting customer needs, building quality products and services, encouraging innovation and creativity and gaining employee commitment. Organizational performance is the ability of an organization to fulfill its mission through sound management, strong governance and a persistent rededication to achieving results (Gathungu \& Mwangi, 2012). Mclvor, Humphreys, Wall and McKittrick (2013) proposed that firms delivering services must broaden their examination of productivity from the conventional company-oriented perspective to a dual company-customer perspective. This broadened approach can help reconcile conflicts or leverage synergies between improving service quality and boosting service productivity. In this study organizational performance will be measured in terms of efficiency, compliance to policies and quality service.

Internal environment includes situational factors within the organization which are largely the result of decisions of the management process, most times under management control (Maslova, Kulchitskya \& Penzina, 2017). Therefore, internal environment can be described as the resources, behaviour, strengths, weaknesses, synergy and distinctive completeness within or internal to the organization. Kuratko, Hornsby and Covin (2019) indicate that an organization uses different types of resources produces synergy or synergy within an organization which leads to the development of strengths of weaknesses over a period of time. In this study internal environment will be measured in terms of organizational culture, employee competency, leadership style and organizational structure. Halmaghi, Iancu and Bacila (2017) observe that the organizational culture of an organization presupposes the existence of a system of values, ideals, beliefs and common conduct rules that unite members of an organization. According to Alrawi, Hamdan, Al-Taie and Ibrahim (2018) organizational culture is commonly used to describe the internal environment of an organization because it is of particular importance in making the organization more efficient and has a long-term influence on it. The distinctive sign of solid organizational identity is the existence of a strong organizational culture. Therefore, in order to describe the internal environment of an organization, organizational culture is frequently used as it has a high importance in streamlining the organization's work.

Employee competencies are a list of skills and behaviors that are specific and well defined and are used to layout an organization's performance expectations for a job or the organization's culture as a whole (Osei \& Ackah, 2015). According Li and Atuagene-Gima (2016) employees' creativity makes an important contribution to organizational innovation, effectiveness and survival. Therefore, organizations need to create the organizational contexts that are most supportive to idea generation and creative thinking. Thus, for employees to be creative there must be an internal work environment that supports and nurtures the process of creativity. In order to improve business environment therefore, managers should improve the skill and motivational level or conditions of the employee. Ibrahim and Kelly (2016) indicate that leadership style is the behavior or means used by the leaders to deal with its subordinates to achieve the goals or objectives which already become a common commitment. Leadership styles affect everyone from senior management to the newest college intern. According to Nauman, Khan and Ehsan (2017) the style of leadership creates the corporate culture that influences the organization and its performance. Leadership style in an organization is one of the factors that play significant role in enhancing or retarding the interest and commitment of the individuals in the organization. Therefore, Leadership style can be said to be a leader's approach to providing direction, implementing plans, and motivating people. 
International Journal of Business Management, Entrepreneurship and Innovation, Volume 3, Issue 3, 2021, PP 123-138, ISSN 2707-8027

\section{BMED}

The business environment today is so dynamic that the decision to structure and re-structure has become paramount. Child (2015) posits that the purpose of structure is to contribute to the successful implementation of objectives by allocating people and resources to necessary tasks and design responsibility and authority for their control and coordination. Nelson and Quick (2016) organizational structure institutionalizes how people interact with each other, how communication flows and how power relationships are defined. Therefore, it can be concluded that the performance of an organization is influenced by the structure adopted by that organization. World Vision started operating in Kenya in 1974. The establishment of the organization was during the Sahel draught which took place in 1973. Immediately after its establishment, the organization started providing sponsorship programs to children and their families. The organization also initiated projects to help the communities in Turkana that were suffering from famine. By 1980s, the organization had established various projects in the country that supported more than sixteen thousand children. Some of the activities included the provision of healthcare, education, agricultural assistance, literacy, vocational training and developing water systems. From 1981 to 1990 child sponsorship grew to fifty-two thousand three hundred and fifty-three $(52,353)$, emphasizing education, nutrition, and immunization.

The organization is dedicated to serving young children. World Vision Kenya is an international Christian humanitarian organization which is fully dedicated to working with children, families and communities worldwide to reach their full potential by addressing the causes of poverty and injustice. The organization partners with communities, the government, sponsors, donors and corporates to realize a global strategy which is to build brighter futures for vulnerable children. World Vision Kenya has a vast program reach in Kenya, with Area Programs (APs) - long-term development programs, spread across 35 counties, nationwide. Being an international organization, management team needs to be very strategic in decision making so as to fully meet the goals and objectives which cut across different boundaries. One of the values of World Vision is that "We value people" hence World Vision does not discriminate on religion, ethnic group or even gender. World Vision Kenya (WV) is headed by the National Director (ND) and a team of departmental directors

\subsection{Statement of the Problem}

The business environment is continually changing and challenging organizations in multiple dimensions. The internal environment consists of variables that are inside the organization and typically within the short-run control of top management. These variables form the context within which the corporation exists (Wheelen \& Hunger, 2017). The major challenge is the continuous change in the internal environment and an organization has to adjust its internal environment according to this change. World vision in Nairobi operates in a very dynamic environment. These changes that keep happening in the environment whether anticipated or not determine the strategic objectives that World vision in Nairobi adopts in order to remain relevant in relation to its mission and vision. A study by Alshura and Assuli (2017) examined the impact of internal environment on performance excellence in Jordanian public universities from faculty points of view and a statistically significant and positive correlation was found between overall internal organizational environment. Kawiti (2017) study assessed the effect of Internal Factors on Non-Financial performance of Firms: A Case of DHL and established that information technology is a major contributor organizations success and information systems offer organizations competitive and 
International Journal of Business Management, Entrepreneurship and Innovation, Volume 3, Issue 3, 2021, PP 123-138, ISSN 2707-8027

effective communication channel. Zain and Kassim (2018) study investigated the influence of internal environment and continuous improvements on firm's competitiveness and performance and the firm's internal environment was found to have significant positive influence on the competitiveness of the firms. Therefore, this study sought to investigate the influence of internal environment on organizational performance of World Vision in Nairobi City County, Kenya.

\subsection{Objectives of the Study}

\subsubsection{General Objective}

The general objective of this study was to investigate the influence of internal environment on organizational performance of World Vision in Nairobi City County, Kenya.

\subsubsection{Specific Objectives}

The study specifically aimed at:

(i) Examining the influence of organizational culture on the organizational performance of World Vision in Nairobi City County, Kenya.

(ii) Establishing the influence of employee competency on the organizational performance of World Vision in Nairobi City County, Kenya.

(iii) Determining the influence of leadership style on the organizational performance of World Vision in Nairobi City County, Kenya.

(iv) Finding out the influence of organizational structure on the organizational performance of World Vision in Nairobi City County, Kenya.

\subsection{Literature Review}

This chapter presents theoretical literature review, empirical literature review, summary of the literature reviewed and gaps and conceptual framework.

\subsection{Theoretical Literature Review}

\subsubsection{Resource Based View Theory}

This study will employ the Resource-Based View (RBV) theory as argued by Wernerfelt (1984). The theory argues that a firm has the ability to achieve and sustain competitive advantage if it possesses resources that are valuable, rare, imperfectly imitable and non-substitutable. Not all resources are strategically relevant within an organization. The goal of an organization is to ensure it has access to and control of valuable resources by developing and securing all the relevant resources either internally or externally.

For the sustainable competitive advantages firms are forced to rely on a multitude of outside suppliers for parts, software, knowhow and sales and in doing so gain access to valuable resources and external capabilities (Langlois, 2010). The argument here fits with the need and factors that lead to a certain response strategy decisions in firms; whether they are cost reduction, new product/services introduction, focus on core competencies or labour flexibility and how they improve organizational performance. Barney (1991) states that, "sustainable competitive advantage is derived from resources that are valuable, rare, imperfectly imitable (due to pathdependence, causal ambiguity, and social complexity), and no substitutable". A resource-based 
International Journal of Business Management, Entrepreneurship and Innovation, Volume 3, Issue 3, 2021, PP 123-138, ISSN 2707-8027

\section{BMET}

view of the firm accepts that attributes related to past experiences, organizational culture and competences are critical for the success of the firm.

\subsubsection{Durkheim's Theory of Culture}

This theory was developed by Emile Durkheim (1890). It explains culture as the emergent net of representations, holistically comprehending the in-depth set belief, value, and symbolic structures of natural entirety such as tribal communities in which he gave such close observation. The theory argues that a bountifulness of work in a firm's sociology involves the substance of what the culture term seems to consist, even if it seems impossible. It is through culture that an organization influences the tasks and achievement of the objectives of an organization. According to Zheng and McLean (2010), although subcultures may strengthen integration with the entire organization, they could also provide centers of disagreement. Cultural gaps are likely to happen on status, professional or divisional lines. Proof of existing subcultures is found in various discursive practices in organizations: in the different accounts employees on divergent organizational categories give organizational occurrences in a specialized form of speech that professionals in some firms share wholly with colleagues that are outside the firm than those that are within; and in various expressive symbols everywhere which subgroups come together in the production of their mutual sense of mission. The theory is important to the study as culture develops good working relationships and encourages ethical contact between workers. It also allows workers to make decisions in circumstances where there are no formal guidelines or regulations, circumstances that have not been encountered but which enhance the organization's performance.

\subsubsection{Contingency Theory}

Contingency theory is based on the original works of Burns and Stalker (1961) and was later amplified by Lawrence and Lorsch (1967), who emphasized the need to examine the role of contingencies or situations on organizations and their behavior. The theory argues that organizations have to be integrated and differentiated to an extent of optimality, contingent upon the level of environmental uncertainty. Okeyo (2013) argue that the essence of contingency theory is that best practices depend on the contingencies of the situation and thus helps analyze situations and determine what variables influence the strategic decisions. Contingency theory posits that organizational effectiveness is achieved by matching organizational structure to contingencies. The contingency theory underscores the role of strategic alignment which enhances the fit between an organization strategic priorities and its environment, which in turn leads to support organizational performance (Morton \& Hu, 2014). According to Walter et al. (2013 the underlying construct of strategic fit is fundamental as it leads to a higher level of organizational consensus associated with improved coordination and cooperation in the strategy and ultimately with organizational performance. It is imperative to note that effectiveness in contingency theory has a wide range of meaning that includes, but is not limited to, efficiency, profitability workers at is faction and ultimately culminating better firm performance. This study holds the proposition that organizations largely depend on the fit between organizational structure and contingencies. Hence, good structural co-alignment matched with prudent strategic choice and successful implementation usually leads to superior performance. In the currents study, the use of contingency theory is an endeavour to explain how organizational structure influences organizational performance. 
International Journal of Business Management, Entrepreneurship and Innovation, Volume 3, Issue 3, 2021, PP 123-138, ISSN 2707-8027

\section{BME}

\subsubsection{Expectancy Theory}

This study will be guided by Expectancy theory proposed by Vroom (1964). Expectancy theory is a cognitive process theory of motivation that relies on the principle of belief that individuals the amount of effort put towards a certain task, the end results attained from it and the benefit acquired has a mutual relationship. Vroom (1964) observes that people's performance rely on person's characteristics such as personality, skills, knowledge, experience and abilities. It was also found that effort, performance and motivation are linked in a person's motivation. According to Heneman and Schwab (2012) expectancy theory provides guidelines for enhancing employee motivation by altering the individual's effort-to-performance expectancy, performance-to-reward expectancy, and reward valences. According to Vroom (1964) a person will conduct himself/herself or behave in a particular way because of the motivational factors vested on that particular behavior due to expected results out of the behavior. In other words, the person selected behavior is based on the motivation and is characterized by the appeal of the end results. This motivation can be categorized into three factors namely; Valence, expectancy and instrumentality. First, Valence is the person's strength for his/her favorite such as reward. For example employees will strive to have a positive outcome in their place of work. Second, expectancy is the likelihood that a specific act or attempt would result to a specific performance. These particular outcome achieved by an individual relies not just the options he/she makes rather on activities further than his/her control. Third, instrumentality is the likelihood that performance will result to the expected outcome. This theory is relevant to the study as it state that work effort is determined by a combination of the individual effort to performance expectancy, performance to outcome expectancy and the valences that the person feels for those outcomes. The expectancy to performance increases by improving the employees' ability and confidence to perform the job. The performance to expectancy increases by measuring performance accurately, distributing higher rewards to better performers and showing employees that rewards are performance based. In other words a person will receive a reward the moment he/she fulfils his/her task. This means that a better employee empowerment will motivate them and hence lay loyalty towards the attainment of organization goals.

\subsection{Empirical Literature Review}

\subsubsection{Organizational Culture and Performance}

A study by Nikpour (2017) investigated the impact of organizational culture on organizational performance: The mediating role of employee's organizational commitment. This study was descriptive and correlational research that was conducted through the survey method. The study population consisted of all employees in education office of Kerman province and 190 persons were selected as volume of sample by using Cochran's formula. The findings of the research indicated that organizational culture had an indirect impact on organizational performance through the mediation of employee's organizational commitment that the extent of indirect impact was significantly higher than direct impact. Ahmed and Shafiq (2014) study investigated the impact of organizational culture on performance of telecom sector. This study was conducted in different Bahawalpur based franchises of telecom companies. Quantitative approach was adopted in which a questionnaire is used to collect the data. The questionnaire is adopted from a previous study. The findings indicate that all the dimension of the culture influence the different perspective of organizational performance. Sengottuvel and Aktharsha (2016) study investigated the influence of organizational culture on organizational performance in information technology sector. For this 
International Journal of Business Management, Entrepreneurship and Innovation, Volume 3, Issue 3, 2021, PP 123-138, ISSN 2707-8027

\section{IBMED}

study, a sample of 210 employees was drawn from the population of 1200 Information Technology (IT) employees using a structured questionnaire from a Leading IT company. The results of Partial Least Square Path Modelling (PLS-PM) have shown that Strategic emphases found to be the significant predictor of Organizational performance. Besides, all dimensions of Organizational Culture combined together, explain significant variation in the performance of IT organization.

\subsubsection{Employee Competency and Performance}

Osei and Ackah (2015) study examined the relationship between employee's competency and organizational performance in the pharmaceutical industry. A total of 280 respondents were sampled for the field survey. The data acquired was used to test the hypothesis stated for this study. The linear regression analysis output supported the hypothesis stated for this study and this suggests that firms are aware of the enormous benefit that they enjoy as a result of having in place an effective and efficiency workforce. Mufti, Parvaiz, Wahab and Durrani (2016) study investigated the influence of human resource competencies on organizational performance: A Study on Banking Sector Managers in Pakistan. A cross sectional non-experimental survey design was used to test the hypothesis. Data was collected using through structured questionnaires from sample of 985 middle and entry level managers working in seven private banks using random sampling technique. Analysis was conducted using correlation and regression. The results revealed that the aforementioned human competencies were positively and significantly related to organizational performance. A study by Salman, Ganie and Saleem (2020) assessed employee competencies as predictors of organizational performance: A Study of Public and Private Sector Banks. The study employed a cross-sectional research design, and the data were collected through a structured questionnaire using convenience sampling. Confirmatory factor analysis was used to check the reliability and validity of the dimensions, and the proposed hypotheses were tested by using structural equation modelling. The results indicated a positive and significant impact of selected employee competencies on organizational performance except for self-competence, which showed an insignificant and negative effect.

\subsubsection{Organizational Structure and Performance}

Agatha (2013) study investigated the influence of organizational structure on organizations performance: A Case Study of Mbarara University of Science and Technology. Data was collected using questionnaires and interviews and during data collection simple random sampling and stratified sampling methods were used. Both quantitative and qualitative research methodologies were also used as a sample of 70 respondents was selected from the study area. The study found out that there is a relationship between organizational structure and service delivery and that the structure of Mbarara University of Science and Technology has an effect on its financial management. Latifi and Shooshtarian (2014) carried out a study on the effects of organizational structure on organizational trust and effectiveness. The population was drawn from a sample of employees of corporations operating in medium and large industries in Fars Province in Iran. The results have shown that there is a significant relationship between organizational structure and trust dimensions. There is a significant relationship between organic structure and effectiveness, and there is no significant relationship between mechanistic structure and effectiveness dimensions. Onono (2018) study examined the impact of organizational structure on performance at General Electric Africa. A descriptive research design was used in this study. The target population was 290 employees at General Electric in the Sub Sahara Africa region based in four General Electric 
International Journal of Business Management, Entrepreneurship and Innovation, Volume 3, Issue 3, 2021, PP 123-138, ISSN 2707-8027

\section{IBMED}

sites locations in Nairobi in Kenya, Lagos in Nigeria, Luanda in Angola and Johannesburg in South Africa. Structured questionnaire was used to collect quantitative data. The study found that organizational structure embraced in an organization affected the speed and accuracy of decision making and directly influenced the learning and growth culture within the organization.

\subsubsection{Leadership Style and Performance}

Mureithi (2012) study examined the effects of leadership style on organizational performance: A Survey of Tertiary Institutions in Nyeri Town. The research used the survey design methodology. The study targeted the tertiary institutions in Nyeri town. It focused on the 305 employees of 16 colleges who were categorized into middle management, low level management and the teaching and non-teaching staff. Simple random sampling was used to sample the respondents. Data collected was analyzed using content analysis and descriptive statistics. The study found out that leadership style was a major factor affecting organizational performance. Ojokuku, Odetayo and Sajuyigbe (2017) study evaluated the impact of leadership style on organizational performance: A case study of Nigerian banks. The study followed a survey design, and employed evaluative quantitative analysis method. Analysis was based on primary data generated through a structured Multifactor Leadership Questionnaire (MLQ) administered on respondents. The result showed that while transactional leadership style had significant positive effect on performance, transformational leadership style had positive but insignificant effect on performance. A study done by Al-Khajeh (2018) explored the impact of leadership styles on organizational performance. The focus was on six major leadership styles -transformational, transactional, autocratic, charismatic, bureaucratic and democratic. In this study, both primary and secondary research has been conducted. The primary research has been done using the quantitative approach, with the help of survey instrument, based on a survey questionnaire. The secondary research has been done through the review of previously established literature for achieving the research objectives. The findings suggested that charismatic, bureaucratic and transactional leadership styles have negative relationship with organizational performance.

\subsection{Research Methodology}

This study used descriptive survey research design. According to Kothari (2004) descriptive design is used when describing the characteristics of a phenomenon in a particular situation. Descriptive research design was also helpful to the study because it results in rich data that is collected in large amounts and the data collection allows for gathering in-depth information that may be either quantitative or qualitative in nature. This allowed for a multifaceted approach to data collection and analysis. Therefore, the design helped in obtaining information on the current status of the influence of internal environment on performance of World Vision. The unit of analysis was World Vision in Nairobi City County, Kenya. The accessible population was 95 respondents comprising of 10 managers and 85 support staff. The study conducted a stratified sampling method to sample the accessible population so as to ensure that all the cases are well represented. Simple random sampling method was used to select the respondents. According to Mugenda and Mugenda (2003) a sample size ranging between $10 \%$ to $50 \%$ is representative of the accessible population. This study adopted a 50\% sample size from the accessible population which was 48 respondents comprising of 5 project managers and 43 project team members. Primary data was collected using questionnaires. The use of questionnaires was possible because the sampled respondents were considered to understand that study questions which minimizes interpretations of the questions 
International Journal of Business Management, Entrepreneurship and Innovation, Volume 3, Issue 3, 2021, PP 123-138, ISSN 2707-8027

BE:

thus making it cheaper and faster to collect data. The questionnaires were divided into different sections covering the objectives of the study. Likert scale was used to allow the respondents to express their level of agreement to listed questions pertaining to each study objective. Questionnaires were administered to all the respondents.

The researcher first contacted the top level management of the organization to affirm his intention on carrying out the study and to clarify the significant of the study and the commitment required from the management. Questionnaires administered through pick and drop method and picked later after two weeks. The researcher made a follow up through phone calls and in addition, visited the respondents before the stated period to remind them on the importance of responding to the questionnaire. Primary data from the field was edited to eliminate errors that could have been made by the respondents. Coding was done to translate question responses into specific categories so as to organize and reduce research data into manageable summaries. Quantitative data was analyzed using descriptive statistics such as mean and standard deviation and presented in form of tables and figures where applicable with the aid of Statistical Package for Social Sciences (SPSS) version 20.0. Content analysis technique was used to analyse information obtained from the open ended questions and reported in narrative form. Inferential statistics such as correlation analysis and multiple regressions were used to determine the relationship between variables. Results of Inferential Analysis

\subsection{Data Analysis Results}

Table 1: Correlation Analysis

\begin{tabular}{|ll|l|l|l|l|l|}
\hline & $\begin{array}{l}\text { Organizati } \\
\text { onal } \\
\text { culture }\end{array}$ & $\begin{array}{l}\text { Employee } \\
\text { competence }\end{array}$ & $\begin{array}{l}\text { Organizational } \\
\text { structure }\end{array}$ & $\begin{array}{l}\text { Leadership } \\
\text { style }\end{array}$ & $\begin{array}{l}\text { Organization } \\
\text { al } \\
\text { performance }\end{array}$ \\
\hline $\begin{array}{l}\text { Organizational } \\
\text { Performance }\end{array}$ & $\begin{array}{l}\text { Pearso } \\
\mathrm{n} \\
\text { Correl } \\
\text { ation } \\
\text { Sig. } \\
(2- \\
\text { tailed) } \\
\mathrm{N}\end{array}$ & 0.781 & $.677^{* *}$ & $.864^{* *}$ & $.667^{* *}$ & 1 \\
& 0.000 & 0.002 & 0.000 & 0.000 & \\
& 47 & 47 & 47 & 47 & \\
\hline
\end{tabular}

**. Correlation is significant at the 0.01 level (2-tailed).

\section{Source: Survey Data (2021)}

The findings in Table 1 show that the Pearson's $r$ for the relationship between organizational culture and organizational performance is 0.781 . This shows that there is a very strong relationship between organizational culture and organizational performance. This is consistent with a study by Nikpour (2017) that investigated the impact of organizational culture on organizational performance and indicated that organizational culture had an indirect impact on organizational performance through the mediation of employee's organizational commitment.

The Pearson $r$ value between employee competence and organizational performance is at 0.677 which showed a strong relationship between the variables. These findings agree with the findings 
International Journal of Business Management, Entrepreneurship and Innovation, Volume 3, Issue 3, 2021, PP 123-138, ISSN 2707-8027

BME

of a study carried out by Osei and Ackah (2015) study that examined the relationship between employee's competency and organizational performance in the pharmaceutical industry and suggests that firms are aware of the enormous benefit that they enjoy as a result of having in place an effective and efficiency workforce. Organizational structure had a very strong relationship with the organizational performance as indicated by a Pearson $r$ value of 0.864 . The findings agrees with the findings of Agatha (2013) study that investigated the influence of organizational structure on organizations performance and found out that there is a relationship between organizational structure and service delivery and that the structure of Mbarara University of Science and Technology has an effect on its financial management. Leadership style variable strongly related with organizational performance at a Pearson $r$ value of 0.667 . This finding is in concurrence with Ojokuku, Odetayo and Sajuyigbe (2017) study that evaluated the impact of leadership style on organizational performance and showed that while transactional leadership style had significant positive effect on performance, transformational leadership style had positive but insignificant effect on performance.

Table 2: The Table below shows the Model Summary

$\begin{array}{lccll}\text { Model } & R & R & \text { Adjusted } & \text { Std. Error of the Estimate } \\ & & \text { Square } & \text { R square } & \\ 1 & 0.768^{a} & 0.837 & 0.834 & 0.266\end{array}$

\section{Source: Research Data (2021)}

The four independent variables that include; organizational culture, employee competence, organizational structure and leadership style that were studied, explain $83.4 \%$ of the organizational performance of World Vision in Nairobi City County, Kenya as represented by the adjusted R square. This therefore means that other factors not studied in this research contribute $16.4 \%$ of the organizational performance.

Table 3: The Table below shows the Analysis of Variance

\begin{tabular}{lllllll}
\hline Model & & Sum of squares & Df & Mean Square & F & Sig. \\
1 & Regression & 99.853 & 4 & 24.998 & 51.998 & $.000^{\mathrm{a}}$ \\
& Residual & 6.737 & 43 & .071 & & \\
& Total & 106.590 & 47 & & & \\
\hline
\end{tabular}

\section{Source: Research Data (2021)}

Since the significance value, $.000^{\mathrm{a}}$ is less than 0.05 , reflected significance of the model a clear show that organizational culture, employee competence, organizational structure and leadership style influenced the organizational performance of World Vision in Nairobi City County, Kenya. The F computed at a 5\% level of significance was 51.998 which was above 24.963 as the critical value implying that the model was significant. 
International Journal of Business Management,

Innovation, Volume 3, Issue 3, 2021, PP 123-138, ISSN 2707-8027

Entrepreneurship

and IBMED

\begin{tabular}{|c|c|c|c|c|c|c|}
\hline \multirow[b]{2}{*}{$\overline{\text { Model }}$} & \multicolumn{3}{|c|}{ Coefficients } & \multirow{2}{*}{$\frac{\text { Coefficients }}{\text { Beta }}$} & \multirow[t]{2}{*}{$\mathrm{t}$} & \multirow[t]{2}{*}{ Sig. } \\
\hline & & $\bar{B}$ & Std, Error & & & \\
\hline 1 & (Constant) & .729 & .139 & & 2.007 & .000 \\
\hline & Organizational culture & .504 & .081 & 4.201 & 2.525 & .001 \\
\hline & Employee competence & .704 & .082 & 2.063 & 4.900 & .000 \\
\hline & Organizational structure & .648 & .083 & 1.303 & 3.588 & .001 \\
\hline & Leadership style & .844 & .088 & 3.434 & 5.514 & .000 \\
\hline
\end{tabular}

\section{Source: Research Data (2021)}

From the above regression model, holding all the independent variables studied that include; organizational culture, employee competence, organizational structure and leadership style at constant, the organizational performance of World Vision in Nairobi City County, Kenya would be 0.729 . The established regression equation by the study was: $\mathrm{Y}=0.729+0.504 \mathrm{X}_{1}+0.704 \mathrm{X}_{2}+$ $0.648 \mathrm{X}_{3}+0.844 \mathrm{X}_{4}$. As shown in Table 4, organizational culture, employee competence, organizational structure and leadership style had a positive and significant effect on organizational performance as indicated by beta values. The relationships $(\mathrm{p}<0.05)$ are all significant with organizational culture $(\beta=4.201 ; p<0.05)$, employee competence $(\beta=2.063 ;<0.05)$, organizational structure $(\beta=1.303 ; p<0.05)$ and leadership style $(\beta=3.434 ; p<0.05)$. Leadership style was found to have a greater $(84.4 \%)$ on the performance of the organization compared to employee competence $(70.4 \%)$, organizational structure $(64.8 \%)$ and organizational culture $(50.4 \%)$. These results agree with the findings of the Ahmed and Shafiq (2014) study that investigated the impact of organizational culture on performance of telecom sector and the findings indicate that all the dimension of the culture influence the different perspective of organizational performance. Salman, Ganie and Saleem (2020) study assessed employee competencies as predictors of organizational performance and the results indicated a positive and significant impact of selected employee competencies on organizational performance except for self-competence, which showed an insignificant and negative effect. This is also in accordance with Latifi and Shooshtarian (2014) study that examined the effects of organizational structure on organizational trust and effectiveness and found that there is a significant relationship between organic structure and effectiveness, and there is no significant relationship between mechanistic structure and effectiveness dimensions and the finding also concur with a study done by Al-Khajeh (2018) that explored the impact of leadership styles on organizational performance and the findings suggested that charismatic, bureaucratic and transactional leadership styles have negative relationship with organizational performance.

\subsection{Conclusions and Recommendations}

\subsection{Conclusions}

This study concludes that a work environment that possesses organizational culture is driven by purpose and clear expectations. This motivates and inspires employees to be more engaged in their work duties and interactions with others. When employees feel valued and respected at a company are less likely to leave it. An organizational culture represents its public image and reputation. People make assumptions about businesses based on their interactions within and outside of the 
International Journal of Business Management, Entrepreneurship and Innovation, Volume 3, Issue 3, 2021, PP 123-138, ISSN 2707-8027

\section{IBMED}

company. The study concludes that competence among employees ensures that organizationfunded training and professional development activities are cost-effective, goal-oriented and productive. Reduces cost overruns caused by poor performance or miscommunication of job expectations. Outlines employee development and promotional paths within the organization and enables employees to be more proactive beyond their individual roles, by learning additional competencies that are valued by the organization.

The study concludes that the flow of information with an organizational structure can be used to promote faster decision-making. An organized structure creates an efficient and streamlined system that helps improve company operations overall. An organized structure provides employees with the guidance they need to perform at their best every day. Using organizational structures can potentially eliminate conflict between employees. an organizational hierarchy has the potential to foster healthy communication between different divisions and teams. Once duties are delegated to various teams and individuals, others in the workplace will know who to turn to for certain matters. The study concludes that leadership style develops structured and organised pathway for decision making which makes target more visible and clear. The style managers adopt have a profound impact on the people they work with and the outcome of their short and long-term objectives. When leaders lead by example, it can create trust and a positive working environment that enables employees to perform at their best capacity. Building a unique style with the flexibility to switch into other styles when situations change may help enhance the overall leadership effectiveness.

\subsection{Recommendations}

The study recommends that the organization's leaders must communicate not only the values, but also the expected behaviors associated with each value to help the employees understand what is expected, which reduces uncertainty and ensures everyone is aligned on how things should be done at the company. The managers should give employees the right information, the right tools, the right amount of support and the control and power to make decisions. The study recommends that in order to improve competencies, the organization should provide enough resources and motivate its employees. The organization should add an extra element of challenge that include special projects, leading teams, conducting seminars and training or coaching new hires to give employees something new to do, forcing them to sharpen their current skills while simultaneously building new ones.

The study recommends that the organization should look at the current organizational structure and analyze whether its employees know their exact duties, who they supervise and whether they are being used to their maximum potential. Adjust the current organizational structure. Combine or split Functions of some departments which need to work closely together or a part. Develop a new organizational structure plan by simply selecting the new structure that will allow for the most efficiency and productivity. The study recommends that the organizational leaders should take time throughout the day to reflect to improve leadership style and skills. The managers should improve their leadership style by setting examples. Behave the way they expect those who work with them to behave. Listen to their employees with an open mind and implement an open-door policy. They should listen and react decisively and in a fair manner for the common good of everyone involved and with the end goal in mind. 
International Journal of Business Management, Entrepreneurship and Innovation, Volume 3, Issue 3, 2021, PP 123-138, ISSN 2707-8027

BMED

\section{References}

Agatha, T. (2013). The Influence of Organizational Structure on Organizations Performance. A Case Study of Mbarara University of Science and Technology (Master's Project, Bishop Stuart University)

Ahmed, M., \& Shafiq, S. (2014). The impact of organizational culture on organizational performance: A case study on telecom sector. Global Journal of Management and Business Research, 14(3), 1 -11

Al-Khajeh, E. H. (2018). Impact of leadership styles on organizational performance. Journal of Human Resources Management Research, 2(1), 1-10.

Alrawi, K., Hamdan, Y., Al-Taie, W., \& Ibrahim, M. (2018). Organizational culture and the creation of a dynamic environment for knowledge sharing. American Journal of Social and Management Sciences, 2(3), 258-264.

Alshura, M. S. K., \& Assuli, J. A. H. A. (2017). Impact of internal environment on performance excellence in Jordanian public universities from faculty points of view. International Journal of Business and Social Science, 8(1), 45-57.

Atsegbua, K. (2019). Changing Organization: Essays on the Development and Evolution of Human Organization, New York: McGraw-Hill Company.

Bennett, W., Lance, C., \& Woehr, D. (2014). Performance measurement: Current perspectives and future challenges. Oxford: Psychology Press

Derek, B. (2018). The Changing Environment of Business, $2^{\text {nd }}$ Edition: Boston; Kent Publishing Company.

Duncan, R. G. (2018). Characteristics of Organizational Environments and Perceived Environmental Uncertainty. Administrative Science Quarterly, 17(2), 313-327

Gathungu, J. M., \& Mwangi, K. (2012). Dynamic capabilities, talent development and firm performance. DBA Africa Management Review, 2(3), 83-100

Halmaghi, E. E., Iancu, D., \& Băcilă, M. L. (2017). The organization's internal environment and its importance in the organization's development. In Internafional Conference Knowledge-Based Organizafion, XXIII (Vol. 1, pp. 378-381)

Halmaghi, E. E., Iancu, D., \& Băcilă, M. L. (2017). The organization's internal environment and its importance in the organization's development. In International Conference Knowledge-Based Organization, 15(1), 378 - 381

Heneman, H. G., \& Schwab, D. P. (2012). Evaluation of research on expectancy theory predictions of employee performance. Psychological Bulletin, 78(1), 1 - 15

Hine, D., \& Ryan, N. (2015). Small service firms - creating value through innovation. Managing service quality, 9(6), 411-422

Ibrahim, A. B., \& Kelly, J. (2016). Leadership style at the policy level. Journal of General Management, 11(3), 37-46.

Kawiti, M. N. (2017). The Effect of Internal Factors on Non-Financial Performance of Firms: A Case of DHL (Doctoral dissertation, United States International University-Africa).

Kothari, C. R. (2004). Research methodology: Methods and techniques. New Age International

Kuratko, D. F., Hornsby, J. S., \& Covin, J. G. (2019). Diagnosing a firm's internal environment for corporate entrepreneurship. Business Horizons, 57(1), 37-47.

Latifi, M., \& Shooshtarian, Z. (2014). The effects of organizational structure on organizational trust and effectiveness. Polish Journal of Management Studies, 10(2), 73 - 84 
International Journal of Business Management, Entrepreneurship and Innovation, Volume 3, Issue 3, 2021, PP 123-138, ISSN 2707-8027

\section{BMED}

Lawrence, P. R., \& Lorsch, J. W. (2009). Organization and Environment: Managing Differentiation and Integration. Boston, MA, Harvard University Press

Li, H., \& Atuagene-Gima, K. (2016). Product innovation strategy and the performance of new technology ventures in China. Academy of Management Journal, 44( 6), 1123-1134.

Luhangala, H. M., \& Anyieni, A. (2019). Strategy implementation on organization performance: A case of public secondary schools Nyamira County, Kenya. International Academic Journal of Human Resource and Business Administration, 3(5), 394-410

Maslova, E. V., Kulchitskya, E. V., \& Penzina, O. S. (2017). Model of an Organization's Internal Environment Development on The Basis of Human Resource Audit. Journal of Advanced Research in legal and economics, 8(1), 118.

Mclvor, R. Humphreys, P. Wall, P., \& McKittrick, A. (2013). A study of performance measurement in the outsourcing decision. Resource Executive Summary services, 4(3), 1 13

Morton, N. A., \& Hu, Q. (2015). Implications of the fit between organizational structure and ERP: A structural contingency theory perspective. International Journal of Information Management, 28(5), $391-402$

Mufti, O., Parvaiz, G. S., Wahab, M., \& Durrani, M. (2016). Human Resource Competencies and Organizational Performance: A Study on Banking Sector Managers in Pakistan. Journal of Managerial Sciences, 10(1), $12-23$

Mugenda, O. \& Mugenda, A. (2003). Research Methods: Qualitative and Quantitative Approaches. Nairobi: Acts Press

Mureithi, E. W. (2012). The Effects of Leadership Style on Organizational Performance: A Survey of Tertiary Institutions in Nyeri Town (Doctoral dissertation, Kenyatta University).

Nauman, S., Khan, A. M., \& Ehsan, N. (2017). Patterns of empowerment and leadership style in project environment. International Journal of Project Management, 28(7), 638-649.

Nikpour, A. (2017). The impact of organizational culture on organizational performance: The mediating role of employee's organizational commitment. International Journal of Organizational Leadership, 6(1), $65-72$

Ogula, P. (2005). Research Methods Nairobi Kenya. Catholic University of East Africa Publications.

Ojokuku, R. M., Odetayo, T. A., \& Sajuyigbe, A. S. (2012). Impact of leadership style on organizational performance: a case study of Nigerian banks. American journal of business and management, 1(4), 202-207

Okeyo, W. (2013). Entrepreneurial Orientation, Business Environment Business Development Services and Performance of small and Medium Manufacturing Enterprises in Kenya. Unpublished PhD. Thesis.

Olagunju, A., \& Obademi, O. (2012). An analysis of the impact of mergers and acquisitions on commercial banks performances in Nigeria. Pakistan Journal of Social Sciences, 9(1), 139-146

Orodho A. J. (2005). Techniques of writing research proposals and reports in Educational and Social Sciences, (2nd Edition) Nairobi: Kaneja H.P Enterprises

Osei, A. J., \& Ackah, O. (2015). Employee's competency and organizational performance in the pharmaceutical industry. International Journal of Economics, Commerce and Management, 3(3), 1-9. 
International Journal of Business Management, Entrepreneurship and Innovation, Volume 3, Issue 3, 2021, PP 123-138, ISSN 2707-8027

Osei, A. J., \& Ackah, O. (2015). Employee's competency and organizational performance in the pharmaceutical industry. International Journal of Economics, Commerce and Management, 3(3), 1-9.

Oyebanji, J. (2014). Nigerian Business Environment and Organization Effectiveness; Abiola Bookshop Limited

Parmenter, D. (2015). Key performance indicators: developing, implementing, and using winning KPIs. John Wiley \& Sons

Salman, M., Ganie, S. A., \& Saleem, I. (2020). Employee Competencies as Predictors of Organizational Performance: A Study of Public and Private Sector Banks. Management and Labour Studies, 45(4), 416-432.

Sengottuvel, A., \& Aktharsha, U. S. (2016). The Influence of Organizational Culture on Organizational Performance in Information Technology Sector. IOSR Journal of Business and Management (IOSR-JBM), 18(10), 56-64.

Tang, H. (2018). An integrative model of innovation in organizations, Technovation, 18(5), 297309.

Vroom, V. H. (1964). On the origins of expectancy theory. Great minds in management: The process of theory development, 3(2), 239-258

Zain, M., \& Kassim, N. M. (2018). The influence of internal environment and continuous improvements on firms competitiveness and performance. Procedia-Social and Behavioral Sciences, 6(5), 26-32.

This is an open-access article published and distributed under the terms and conditions of the (c) (i) \& Creative Commons Attribution 4.0 International License of United States unless otherwise stated. Access, citation and distribution of this article is allowed with full recognition of the authors and the source. Copyright, content ownership and liability for content herein remain with the authors. 